\title{
Anthropogenic greenhouse gas concentrations and global temperature: a smooth transition analysis
}

\author{
Nektarios A. Michail ${ }^{1}$. Christos S. Savva ${ }^{1}$ (D) . Demetris Koursaros ${ }^{1} \cdot$ Theodoros Zachariadis $^{2}$
}

(c) Springer Nature Switzerland AG 2019

\begin{abstract}
This study examines for the existence of a nonlinear relationship between changes in anthropogenic concentrations of greenhouse gases (forcings) and changes in global temperature, using a smooth transition conditional correlation model. The findings suggest that the correlation between the two is practically zero before a threshold value of anthropogenic concentrations is reached, but rises significantly after this threshold is exceeded. The threshold can be traced back in the mid-1960s, during the years of economic growth in industrialized nations. Thus, the results provide an explanation as to the reason why previous studies had, at times, failed to find a significant relationship.
\end{abstract}

Keywords Global temperature · Anthropogenic concentrations · Conditional correlation

JEL Classification $\mathrm{C} 12 \cdot \mathrm{C} 32 \cdot \mathrm{C} 51 \cdot \mathrm{Q} 50 \cdot \mathrm{Q} 54$

\section{Introduction}

In the post-1990s world, there has probably been no other environmental issue which has attracted more attention than the anthropogenic effect on climate change, and more specifically on temperature increases. In recent years, a growing number of scholars examine the causes of global warming using econometric methods. ${ }^{1,2}$ In general, these studies produced mixed results: some document that human activities merely cause a temporary effect on temperature [3], others that this effect is less significant than usually considered $[13,37]$, while a third strand documents a stronger effect $[8-10,21,33,34,38]$.

\footnotetext{
${ }^{1}$ Econometric methods are used to explore several aspects of climate change, such as the relationship between anthropogenic emissions and climate, the effects of climate change on the output of different economic sectors and the impact of climate on mortality. See [19] for an overview of the approaches.

2 Recently, Mazzocchi and Pasini [25] conducted a comprehensive comparison of studies about the causes of the recent global warming, using both dynamical models (global climate models-GCMs) and data-driven (econometric) methods. They conclude that this combination practice leads to more robust results.
}

This version of the paper is the final version of the working paper "After which threshold do anthropogenic greenhouse gas emissions have an effect on global temperature?"The WP is accessible in the following link: http://www.climateeconometrics.org/wpcontent/uploa ds/2017/02/Nektarios_etal_2017.pdf.

Christos S. Savva, christos.savva@cut.ac.cy | ${ }^{1}$ Department of Commerce, Finance and Shipping, Cyprus University of Technology, P.O. Box 50329, 3603 Lemesos, Cyprus. ' Department of Environmental Science and Technology, Cyprus University of Technology, P.O. Box 50329, 3603 Lemesos, Cyprus. 
Fig. 1 Carbon emissions-million tons carbon (1751-2009). Source: Boden et al. [5]

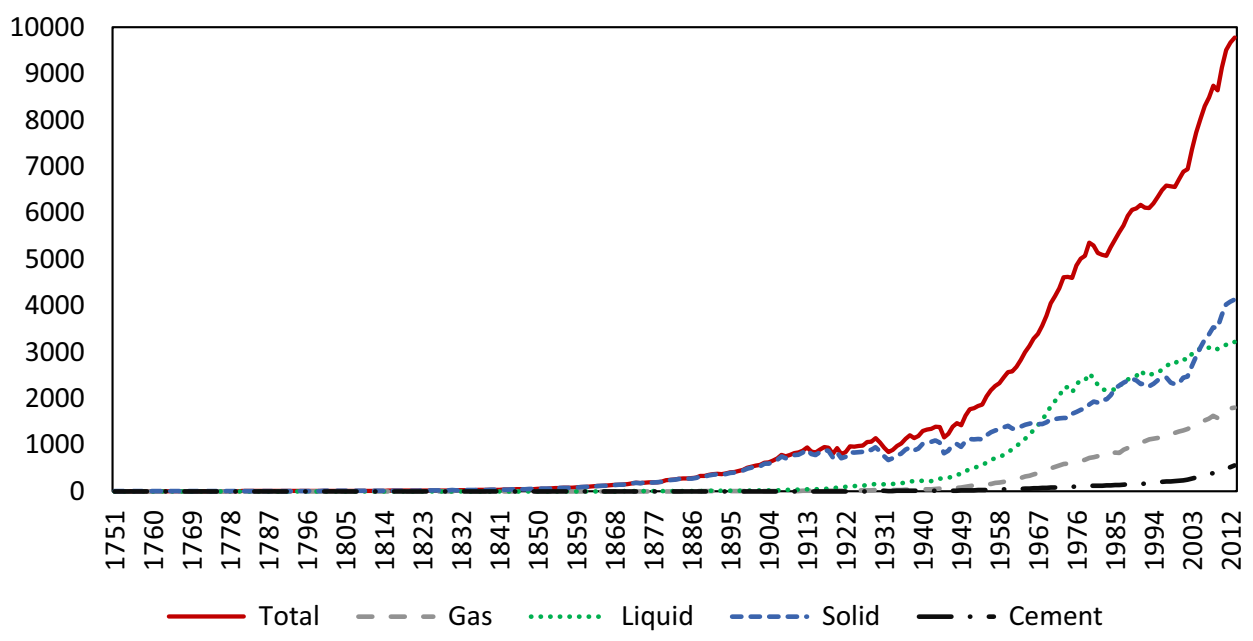

In an attempt to examine whether climate forcings ${ }^{3}$ (and more specifically anthropogenic forcings) are related to global temperature changes, the common methodology employed by the majority of these studies is a variation of Granger causality and cointegration techniques (see for instance [1, 30, 41] among others). Hence, by virtue of the estimation method, the goal of these studies is primarily to investigate the determinants and the behaviour of the long-run relationship.

Through the focus on long-run effects, the literature has thus far not investigated the nature of the short-run relationship between anthropogenic forcings and temperature. Given that changes in the former are expected to have a contemporaneous effect on the evolution (i.e. the change) of the latter, knowledge of this short-run relationship should be valuable to climate scientists.

In addition, the findings of the above studies could be influenced by the potential existence of a nonlinear relationship as the correlation between changes in temperature and changes in anthropogenic forcings is not necessarily constant over time. Intuitively, this suggests that anthropogenic forcings may have an influence on temperature only after a threshold value, making the correlation between the two time-varying.

The possibility of time variability of the relationship was indirectly suggested by Frölicher et al. [12], who measured the extent of MHWs over different periods of time, and suggested that $87 \%$ of them are human-caused, while a similar, time-varying result for oceanic and atmospheric modes was found by Fang et al. [11]. Finally, such a hypothesis is in line with the fact that global temperature increases have only become a pressing issue in the recent

\footnotetext{
${ }^{3}$ A climate forcing is defined as an imposed perturbation of the Earth's energy balance, which can be the result of natural phenomena (natural forcings) or human activities (anthropogenic forcings). A positive or negative forcing tends to make Earth warmer or cooler, respectively [29].
}

past, which may be linked to the fact that a substantial amount of greenhouse gases has accumulated in the atmosphere [32] (chapters 2-4); [17, 24] (chapters 1-3); NASA [20, 28]; among others).

Figure 1, obtained from Boden et al. [5] at the Carbon Dioxide Information Analysis Center (CDIAC), shows the global carbon emissions from 1751 to 2013 . The red solid line is the total effect which consists of various sources of carbon emissions. The grey dashed line corresponds to emissions from combustion of gaseous fuels such as natural gas, with the dotted green line and the blue (dense) dashed line signifying the emissions from liquid and solid fossil fuel combustion, respectively. The black dash-anddot line shows emissions coming from cement production which have been on the rise since the late 1990s.

It is evident from the graph that carbon emissions responsible for greenhouse effects have been surging since the 1960s. Carbon dioxide is the predominant greenhouse gas and is chemically very stable when emitted. Therefore, the largest part of primary emissions of carbon dioxide, as a result of combustion of fossil fuels, remains in the atmosphere for several decades and thus increases greenhouse gas concentrations-which in turn increases anthropogenic climate forcings. Hence, the post1960 surge in carbon emissions is associated with a similar exponential rise in anthropogenic climate forcings, which highlights the importance of exploring econometrically the existence of nonlinear and time-varying relationships in the climate system. Furthermore, this is in line with Yin et al. [42], who show that oceanic heat was built up in the oceans since the 1990s and emerged recently.

In order to formally test the hypothesis of a nonlinear relationship in the correlation between the change in anthropogenic forcings and the change in temperature anomaly, this paper employs a time-varying conditional correlation model. To our knowledge, this is the first attempt to apply such a model to examine whether the 
correlation between temperature anomaly and anthropogenic forcings is stable or changes over time. Importantly, our work departs from the usual estimation efforts made by the existing literature in an essential way since it examines the drivers of short-run variation in the relationship between changes in global temperature anomaly and changes in anthropogenic forcings and does not focus solely on long-run estimates. Furthermore, the methodology employed allows us to account for the noise in the series by employing a $\operatorname{GARCH}(1,1)$ structure for the residuals and thus reach more precise estimates.

The main finding of this study suggests that correlation between the two variables is essentially zero up to a specific level of anthropogenic forcings, while it jumps to 0.54 after this level is exceeded. Intuitively, this suggests that once the threshold is exceeded both variables (change in anthropogenic forcings and global temperature) move in the same direction. The changing point in correlation lies in the 1960s, during the years of the post-WWII economic boom, when a substantial amount of additional greenhouse gases (compared to the pre-industrial era) had started accumulating in the atmosphere due to the burning of fossil fuels from human activities. Furthermore, an additional threshold is located in the 1990s after which correlation jumps to 0.95 .

The findings underline the importance of economic activity and its adverse effects on anthropogenic forcings. At the same time, they confirm the view that is widely shared among climate scientists and declared by the United Nations Intergovernmental Panel on Climate Change, that humans are the main cause of the current global warming [20].

The rest of the paper is organized as follows: Sect. 2 presents the econometric methodology, Sect. 3 overviews the data used in the estimation, and Sect. 4 presents the empirical findings. The paper ends with a summary and conclusions.

\section{Econometric methodology}

As already discussed, the literature investigating the effects of the anthropogenic interpretation of global warming (i.e. whether increases in atmospheric anthropogenic forgings have raised global temperature) focuses solely on long-run relationships. Furthermore, an important caveat of the analyses is that they do not allow for the possibility of a nonlinear relationship between the change in anthropogenic forcings and the change in global temperature, after controlling for non-anthropogenic factors. ${ }^{4}$

\footnotetext{
${ }^{4}$ An exception is the work of Pasini et al. [31] where neural network models are employed to reveal nonlinear relationships.
}

In addition, to our knowledge there is no study to examine whether these correlations change over time, a feature that standard regression models fail to accommodate.

To address this, we propose the use of the smooth transition conditional correlation (STCC) model (see $[4,35]$ ) to test whether correlations between the change in global temperature and changes in anthropogenic forcings are time-varying. ${ }^{5}$

Consider a time series of two variables $\left\{y_{t}\right\}, t=1, \ldots, n$, namely temp $p_{t}$ and $\Delta z_{t}\left(\right.$ i.e. $\left.y_{t}=\left[\text { temp }_{t}, \Delta z_{t}\right]^{\prime}\right)$, the stochastic properties of which are assumed to be described by the following model:

temp $_{t}=\beta_{0}+\sum_{k=1}^{p} \beta_{1, \kappa}$ temp $_{t-k}+\sum_{l=1}^{q} \beta_{2, l} x_{t-l}+\sum_{b=1}^{r} \beta_{3, b} \Delta z_{t-b}+\varepsilon_{1 t}$

where temp $p_{t}$ refers to the change in the global mean temperature anomaly (sea and land combined, as in [3]) at time $t, x_{t}$ refers to non-anthropogenic forcings and $\Delta z_{t}$ refers to the change in anthropogenic forcings. ${ }^{6,7}$ Since not all emissions remain in the atmosphere as some are dissolved, what should matter is the change in forcings and not emissions per se. As such, using the change in anthropogenic forcings instead of emissions better captures the underlying dynamics in the world environment, with regards to the human effects on climate.

Continuing with the STCC model, the second equation follows a similar process such that:

$$
\begin{aligned}
\Delta z_{t}= & \delta_{0}+\sum_{k=1}^{p} \delta_{1, \kappa} \Delta z_{t-k}+\sum_{l=1}^{q} \delta_{2, l} \text { temp }_{t-l} \\
& +\sum_{b=1}^{r} \delta_{3, b}\left(1-G\left(\text { time } ;_{g} ; c_{g}\right)\right) \text { growth }_{t-b} \\
& +\sum_{b=1}^{r} \delta_{4, b} G\left(\text { time }_{\gamma_{g}} ; c_{g}\right) \text { growth }_{t-b}+\varepsilon_{2 t},
\end{aligned}
$$

\footnotetext{
${ }^{5}$ Before we proceed to the estimation of our model, described by Eqs. (1) and (2), we first test our assumption of nonlinearities based on time transition effects. For this purpose, we use the Lagrange multiplier (LM) test statistic developed by Teräsvirta [39]. This LM test examines whether a linear model should be employed instead of a nonlinear one. The results of the test offer strong support for the presence of nonlinearities in Eq. 2, while for Eq. 1 fail to reject the hypothesis of a linear specification. For further details on STR models and model building, including testing, we refer to Teräsvirta et al. [40].

${ }^{6}$ An appendix with further details and sources of the data, and tables and figures, are located at the end.

7 Since changes are employed in econometric methodology, the estimates represent short-run variations. An interesting path for further research would be the threshold cointegration in the case where the levels are related only when specific threshold levels are exceeded. However, this question remains open for further research.
} 
where temp $p_{t}, x_{t}$ and $\Delta z_{t}$ are defined as in (1) and growth ${ }_{t}$ refers to world GDP growth at time $t / n$ (the time is rescaled by the sample size to make the results comparable across different sample sizes). ${ }^{8}$

Since the abnormal climate change is assumed to be affected by both the enhanced greenhouse effect and the depletion of the ozone layer, the GDP growth is used as a proxy of economic/industrial activity where industrial emissions play a crucial role in both processes. As noted by Babiy et al. [2], the enhanced greenhouse effect is caused by the emissions of carbon dioxide, methane, nitrous oxide and fluorine-containing compounds, and substances, which contribute indirectly to the greenhouse effect (such as nitrogen oxides, carbon monoxide and volatile organic compounds), while atmospheric emissions of acidifying substances such as sulphur dioxide (SO2) and nitrogen oxides (NOx), mainly from the burning of fossil fuels contribute to the formation of ozone at low level. ${ }^{9}$

To capture possible temporal changes in the effects of growth on the change in anthropogenic forcings, we let $G\left(\right.$ time; $\left.\gamma_{g}, c_{g}\right)$ be a logistic function (bounded by zero and unity), where time is a variable that measures time and acts as the transition function, $\gamma_{g}$ a coefficient that accounts for the speed of adjustment from one regime to the other (i.e. it defines the slope of the transition function), while $c_{g}$ determines the mid-point of the change in time (i.e. the inflection point of the logistic transition function).

$G\left(\right.$ time $\left.; \gamma_{g}, c_{g}\right)=\frac{1}{1+\exp \left(-\gamma_{g}\left(\text { time }-c_{g}\right)\right)}$.

The logistic function is monotonically increasing in transition variable (time), with $G\left(\right.$ time; $\left.\gamma_{g}, c_{g}\right) \rightarrow 0$ as $\left(\right.$ time $\left.-c_{g}\right) \rightarrow-\infty$ and $G\left(\right.$ time; $\left.\gamma_{g}, c_{g}\right) \rightarrow 1$ as (time $\left.-c_{g}\right) \rightarrow+\infty$. In this work, we explore the idea that there are two distinct regimes in the behaviour of economic growth (industrial activity) on the change in anthropogenic forcings $\left(\Delta z_{t}\right)$, namely period with low effects and period with high effects. The logistic function can define the period with low effects (values of $G\left(\right.$ time; $\left.\gamma_{g}, c_{g}\right)$ "close" to zero) and the period with high effects (values of $G\left(\right.$ time; $\left.\gamma_{g}, c_{g}\right)$ "close" to unity). The slope parameter $\left(\gamma_{g}\right)$ indicates how rapid the transition from 0 to 1 is as a function of time, while $c_{g}$ determines when the transition occurs.

\footnotetext{
${ }^{8}$ Based on SIC criterion and without any loss of generality, the lag order is set to one for all variables.

9 For an extensive analysis on this issue, we refer to Meinshausen et al. [26].
}

In order to model the volatile behaviour of the series (see Figs. 2 and $5 b)^{10}$ and to capture any temporal effects in the error volatilities and correlations, the error processes of Eqs. (1) and (2) are assumed to follow the process

$\varepsilon_{t} \mid \Psi_{t-1} \sim N\left(0, \Sigma_{t}\right)$,

where $\varepsilon_{t}=\left[\varepsilon_{1 t}, \varepsilon_{2 t}\right]^{\prime}, \psi_{t-1}$ is the information set consisting of all relevant information up to and including time $t-1$, and $N$ denotes the bivariate normal distribution. The conditional covariance matrix of $\varepsilon_{t}, \Sigma_{t}$, is assumed to follow a time-varying structure given by

$\Sigma_{t}=E\left[\varepsilon_{t} \varepsilon_{t}^{\prime} \mid \Psi_{t-1}\right]$,

$\sigma_{1 t}^{2}=\omega_{1}+\alpha_{1} \varepsilon_{1 t-1}^{2}+\xi_{1} \sigma_{1 t-1}^{2}$

$\sigma_{2 t}^{2}=\omega_{2}+\alpha_{2} \varepsilon_{2 t-1}^{2}+\xi_{2} \sigma_{2 t-1}^{2}$

$\sigma_{12, t}=\rho_{t}\left(\sigma_{1 t}^{2} \sigma_{2 t}^{2}\right)^{1 / 2}$

$\rho_{t}=\rho_{0}\left(1-G\left(s_{t} ; \gamma, c\right)\right)+\rho_{1} G\left(s_{t} ; \gamma, c\right)$,

where the conditional variances $\sigma_{1 t}$ and $\sigma_{2 t}$ both follow a $\operatorname{GARCH}(1,1)$ specification which is able to adequately capture the persistence (if any) in second moments. ${ }^{11}$

The sizes of $a_{i}$ and $\xi_{i}(i=1,2)$ determine the short- and long-run dynamics of the resulting volatility series, respectively. Large values of the sum of $\left(a_{i}+\xi_{i}\right)$ coefficients indicate that shocks to conditional variance take a long time to die out, implying persistent volatility. On the other hand, large $a_{i}$ coefficients indicate that volatility reacts quite intensively to new information.

To capture temporal changes in the contemporaneous conditional correlation $\rho_{t} ;$ we follow Berben and Jansen [4] and Silvennoinen and Teräsvirta [35] by letting $G\left(s_{t} ; \gamma\right.$, c) be the logistic function.

$G\left(s_{t} ; \gamma, c\right)=\frac{1}{1+\exp \left(-\gamma\left(s_{t}-c\right)\right)}, \quad \gamma>0$,

where $s_{t}$ is the transition variable, and $\gamma$ and $c$ determine the smoothness and location, respectively, of the transition between the two correlation regimes. ${ }^{12}$ The starting

\footnotetext{
10 See also Campbell and Diebold [7] who employed GARCH specification to approximate volatility component for temperatures in various US cities.

11 Transition functions were also employed for the elements of $\sigma_{1 \mathrm{t}}^{2}$ and $\sigma_{2 \mathrm{t}}^{2}$ (Eqs. 6 and 7). However, the findings suggest no significant presence of different behaviour throughout the period under investigation. Therefore, we proceeded with the estimation of a more parsimonious specification (presented in Econometric Methodology section).

12 The transition function $G\left(s_{t} ; \gamma, c\right)$ is bounded between zero and one, so that, provided there are valid correlations lying between -1 and +1 , the conditional correlation $\rho_{t}$ will also lie between -1 and +1 .
} 
Fig. 2 Change in anthropogenic forcings (1886-2006)

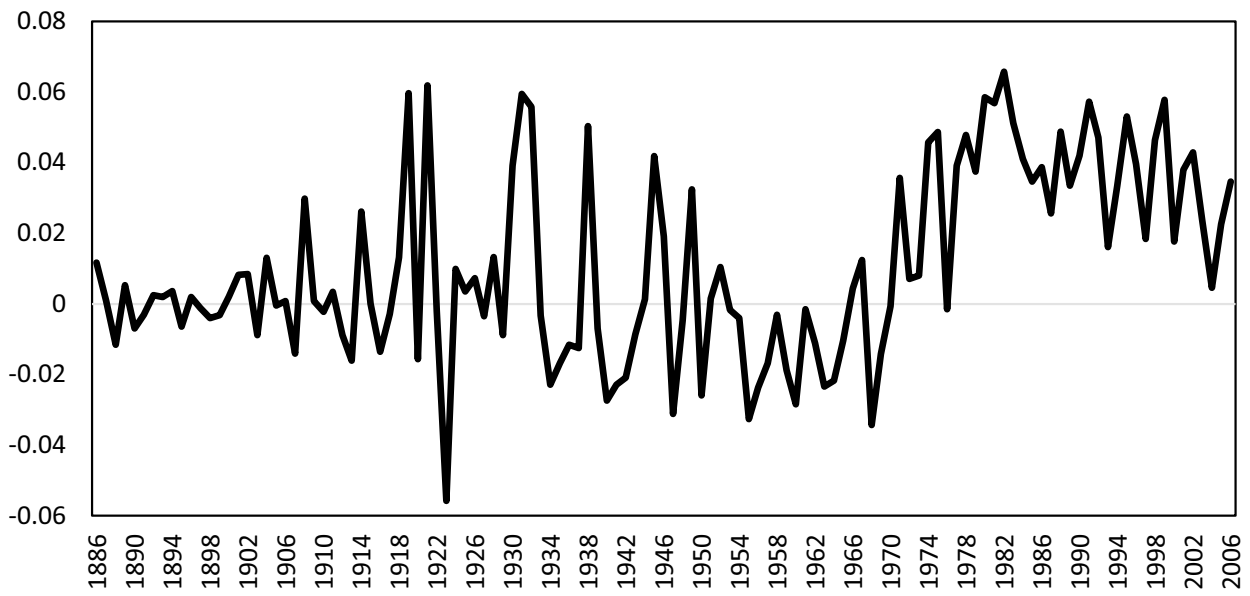

values of $\gamma$ and $c$ are determined by a grid search (see [4]) and are estimated in one step by maximizing the likelihood function. Regarding the transition variable, while any variable can act like one, given that the purpose of this paper is to examine the effect of humans on climate change, we define it as a function of total anthropogenic forcings (at time $t-1$ ). To define when these effects take place in time, we rerun the analysis by employing time as the transition variable, which is described as: $s_{t}=t / n$ (where $t$ denotes time and $\mathrm{n}$ the sample size). ${ }^{13}$

The resulting STCC-GARCH model is able to capture a wide variety of patterns of change. Differing $\rho_{0}$ and $\rho_{1}$ imply that the correlations monotonically increase $\left(\rho_{0}<\rho_{1}\right)$
Prior to employing the STCC specification, a Lagrange multiplier (LM) test against a constant conditional correlation model $[4,35]$ is undertaken. Since null hypothesis of the constant correlation is always rejected, a STCC model is estimated. Subsequently, we examine whether a second transition (in correlations) exists by performing the LM test developed by Silvennoinen and Teräsvirta [36]. ${ }^{16}$ If such evidence is found, then we extend the original STCCGARCH model by allowing the conditional correlations to vary according to two transition variables. The time-varying correlation structure in the double smooth transition conditional correlation (DSTCC) GARCH model is imposed through the following equation:

$\rho_{t}=\rho_{0}\left(1-G_{1}\left(s_{t} ; \gamma_{1}, c_{1}\right)\right)+\rho_{1} G_{1}\left(s_{t} ; \gamma_{1}, c_{1}\right)\left(1-G_{2}\left(s_{t} ; \gamma_{2}, c_{2}\right)\right)+\rho_{2} G_{1}\left(s_{t} ; \gamma_{1}, c_{1}\right) G_{2}\left(s_{t} ; \gamma_{2}, c_{2}\right)$

or decrease $\left(\rho_{0}>\rho_{1}\right)$, with the pace of change determined by the slope parameter $\gamma$. This change is abrupt for large $\gamma$ and becomes a step function as $\gamma \rightarrow \infty$, with more gradual change represented by smaller values of this parameter (in the estimation, the maximum value of the $\gamma$ parameter is set to be 100). ${ }^{14}$ Parameter $c$ defines the location of the transition between the two correlation regimes. In other words, $c$ indicates the mid-point of any change in the correlation due to a change in the transition variable, here anthropogenic forcings. When the transition variable has values less (greater) than $c$, the correlations are closer to the state defined by $\rho_{0}\left(\rho_{1}\right){ }^{15}$

\footnotetext{
13 In practice, we scale $(t / n-c)$ by $\sigma_{t / n}$, the standard deviation of the transition variable $t / n$, to make estimates of $\gamma$ comparable across different sample sizes.

14 Alternatively, one can set $\gamma=\exp (\eta)$ and estimate $\eta$ instead. This transformation is appealing when $\gamma$ is large (see [15]). However, the results remain qualitatively the same.

15 The constant conditional correlation model (Bollerslev, 1990) is a special case of the STCC-GARCH model, obtained by setting either $\rho_{0}=\rho_{1}$ or $\gamma=0$.
}

where each transition function has the logistic form of Eq. (10). The second transition variable is also a function of anthropogenic forcings and as robustness a function of time. Hence, Eq. (11) allows the possibility of a non-monotonic change in correlation over the sample. The parameters $\gamma_{i}$ and $c_{i}(i=1,2)$ are interpreted in the same manner as for the STCC-GARCH model, but to ensure identification we require $c_{1}<c_{2}$ and hence that the two correlation transitions occur at different levels of anthropogenic forcings or points of time.

The likelihood function at time $t$ (ignoring the constant term and assuming normality) is given by

$I_{t}(\theta)=-\frac{1}{2} \ln \left|\Sigma_{t}\right|^{(-1 / 2)}-\frac{1}{2} \varepsilon_{t}^{\prime} \Sigma_{t} \varepsilon_{t}$

where $\theta$ is the vector of all the parameters to be estimated. The log-likelihood for the whole sample from time 1 to $n$, $L(\theta)$, is given by

\footnotetext{
16 For analytical expressions for the test statistics and the required derivatives, we refer to Silvennoinen and Teräsvirta [36].
} 
$L(\theta)=\sum_{t=1}^{n} I_{t}(\theta)$

This log-likelihood is maximized with respect to all parameters simultaneously, employing numerical derivatives of the log-likelihood. To allow for potential non-normality of $\varepsilon_{t} \mid \Psi_{t-1}$, robust "sandwich" standard errors [6] are used for the estimated coefficients.

\section{A preliminary look at the data}

To stimulate the discussion, we first provide an overview of the data underlying our analysis. As usual in the literature, temperature is defined as the temperature anomaly (land and sea temperature combined) with reference to the 1951-1980 base period. Anthropogenic forcings refer to the components of radiative transfer calculation which can be attributed to human actions and are calculated as the sum of six forcings (well-mixed greenhouse gas, ozone, human land use, black carbon snow albedo, the direct effect of tropospheric aerosols and the indirect effect of tropospheric aerosols). All these forcings are the direct or indirect result of human activities.

Similarly, natural forcings refer to factors affecting global temperature which are attributed to natural phenomena. These are specified as the sum of stratospheric aerosols, solar irradiance and orbital variations. Data for all forcings were obtained from Miller et al. [27]. Economic activity, measured as the world GDP, is calculated by summing the domestic production of 21 countries, as produced by Maddison [23]. Further details about the data are delegated to Appendix.

Figures 2 and 3 provide an overview of the evolution of the changes in anthropogenic and natural forcings through time. Changes in anthropogenic forcings depict a volatile behaviour, while natural forcings' behaviour is erratic with unstable increases and decreases. Figure 4, which presents world GDP growth estimates, in billions of 1990 international Geary-Khamis (GK) dollars, also presents an erratic, volatile pattern through time.

The levels of temperature anomaly and the change in temperature anomaly are depicted in Fig. 5a, b. While overall the levels of temperature anomaly are much noisier than the other estimates, they also follow an increasing path, which becomes evident from the late-1970s onwards. Careful observation of Fig. 3 though suggests that natural forcings may have played a significant role in hiding the increase in temperature anomaly in earlier years, as these have mostly contributed to the cooling of the planet from the early 1960s until the mid-1990s. Even though natural forcings have had a strong effect on temperature, the impact of anthropogenic forcings on temperature appears to have been much greater.

Summary statistics reported in Table 1 (panel a) show positive average values for all variables, with the change in the global mean temperature anomaly (tempt ${ }_{t}$ ) having substantially higher (unconditional) volatility, compared to the rest of the variables. The Ljung-Box (LB) statistics for up to 5 lags, for the levels and their squared values, indicate the presence of linear and partially nonlinear dependencies, respectively, in the case of temp ${ }_{t}$ and growth. Linear dependencies indicate some correlation to previous values, while nonlinear dependence suggests that an autoregressive conditional heteroskedasticity specification may be useful to model the second moments. ${ }^{17}$

Table 1 (panel b) presents the correlations among the variables. Measured over the whole sample, the (unconditional) correlations indicate a rather low value. However, these values may conceal substantial differences over time that are not able to be captured by simple statistics. Therefore, while informative, these unconditional correlations cannot indicate whether the correlations hold for the whole sample period.

For instance, Fig. 6 presents the 30-year rolling Pearson correlation between the change in anthropogenic forcings and the change in temperature anomaly. This simple metric highlights the fact that the relationship between the two variables is not only nonlinear but fluctuates over time. During the periods where natural forcings fluctuated around zero (i.e. during the period from 1918 to 1960 based on Fig. 3), correlation reached a value around 0.40 . After the 1970s, the correlation value drops and increases again by the late 1990s.

The above-documented change in correlation gives indications why several models, using long time-series data may have failed, at times, to find a clear relationship between anthropogenic forcings and temperature anomaly. In addition, this behaviour also warrants the

\footnotetext{
17 Although the Ljung-Box statistic for the squared values of the change in anthropogenic forcings $\left(\Delta z_{t}\right)$ does not support nonlinear dependencies, one can observe from Fig. 2 that such series has volatility clustering behaviour and that needs to be incorporated in the model. As Hamilton [16] also notes, the use of models controlling for the variance of the underlying series can lead to better estimates. Such models include ARCH/GARCH specifications which are able to model volatility clustering behaviour. In addition, the findings of the Ljung-Box test for squared variables should be interpreted with caution since the null hypothesis of this test is that the variables under examination are not autocorrelated. Since they seem to be autocorrelated as the Ljung-Box test in levels rejects, the results of the Ljung-Box test for squared variables test may not be reliable. Rejections obtained may well be due to the fact that the levels of the variables are autocorrelated, because this violates the assumptions under which the test statistic has its asymptotic chi-square distribution.
} 
Fig. 3 Natural forcings (18512012) Source: Miller et al. [27]
Fig. 4 World GDP growth (1884-2006) Source: Maddison [23]

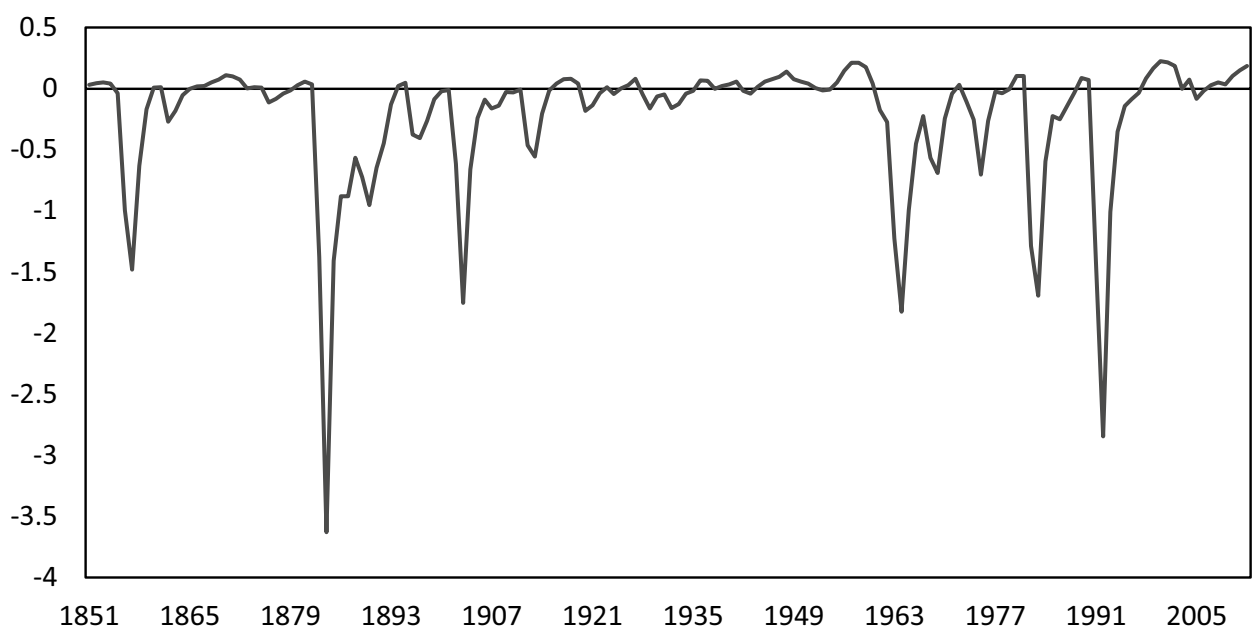

Fig. 5 a Temperature (sealand-air combined) anomaly in Fahrenheit. b Changes in temperature anomaly Source: [14]: GISS surface temperature analysis (GISTEMP) and Hansen et al. [18]

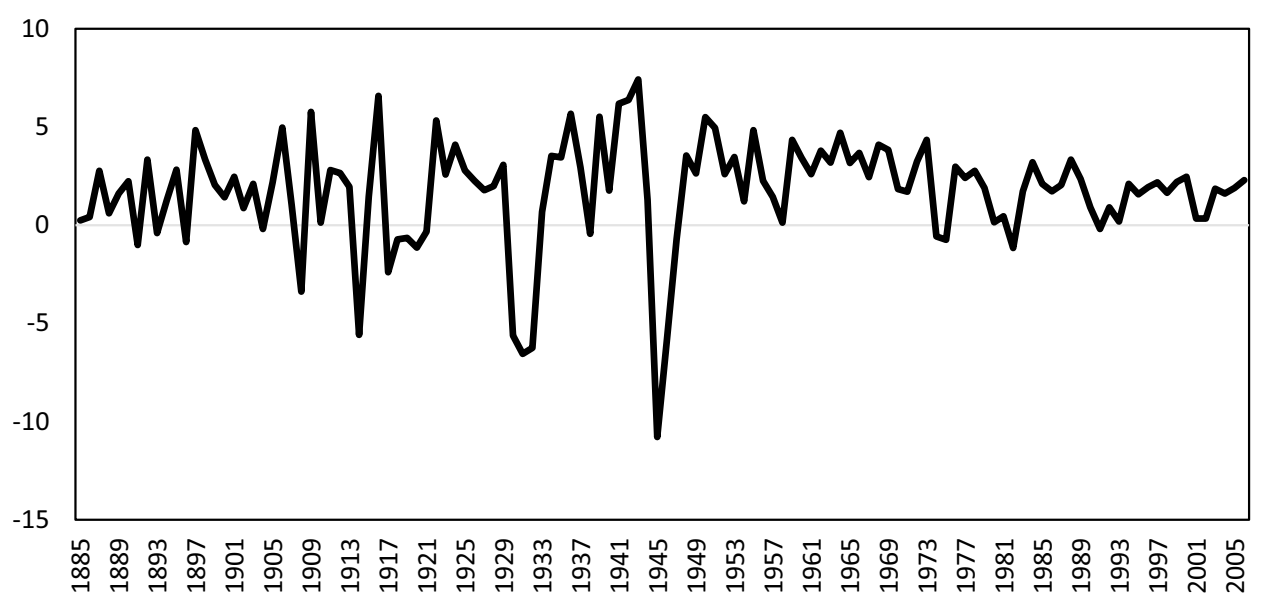

A Temperature (sea-land-air combined) anomaly in Fahrenheit

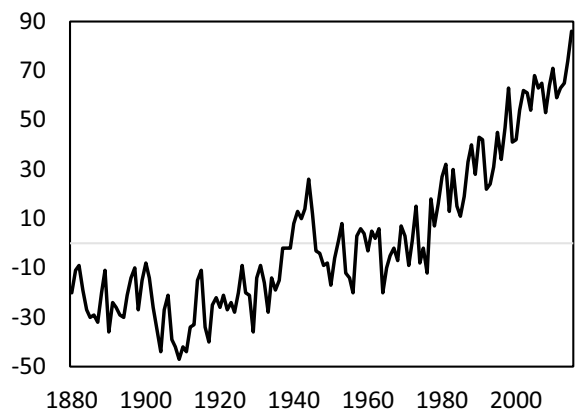

B Changes in Temperature anomaly

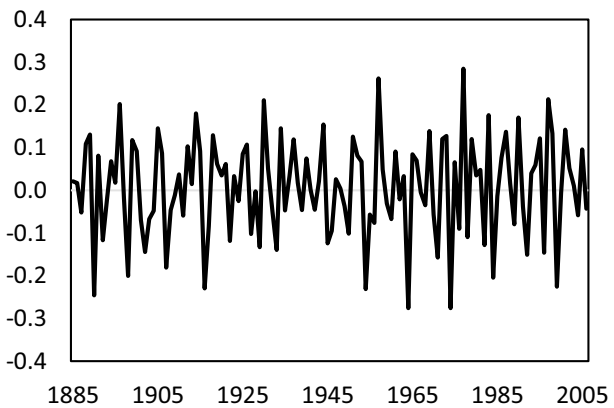

use of alternative methodologies in order to account for the nonlinearity of the relationship. To this extent, the (D)STCC methodology is employed in order not only to account for the nonlinearity of the relationship but also to examine the threshold after which this change in the relationship between temperature and anthropogenic forcings takes place.

\section{Estimation results}

\subsection{Evaluation of structural changes}

In this section, we first look at the conditional correlations of the full sample, assuming that there is no regime shift within the covered time period. Then, we 
Table 1 Preliminary statistics

\begin{tabular}{|c|c|c|c|c|}
\hline & temp $_{t}$ & $\Delta z_{t}$ & $x_{t}$ & Growth $_{t}$ \\
\hline \multicolumn{5}{|c|}{ Panel a: descriptive statistics } \\
\hline Average & 0.659 & 2.300 & -0.267 & 2.788 \\
\hline Stdev & 11.019 & 1.345 & 0.576 & 3.276 \\
\hline Min & -26.000 & -0.390 & -3.630 & -13.888 \\
\hline Max & 30.000 & 7.735 & 0.227 & 8.724 \\
\hline $\operatorname{LB}\left(Y_{t} ; 5\right)$ & $21.988^{* * *}$ & $267.09^{* * *}$ & $55.599^{* * *}$ & $30.837^{* * *}$ \\
\hline $\mathrm{LB}\left(Y_{t}^{2} ; 5\right)$ & $166.98^{* * *}$ & 2.859 & 10.356 & $50.148^{* * *}$ \\
\hline \multicolumn{5}{|c|}{ Panel b: unconditional correlations } \\
\hline temp $_{t}$ & 1 & 0.003 & 0.229 & 0.033 \\
\hline$\Delta z_{t}$ & & 1 & -0.272 & 0.021 \\
\hline$x_{t}$ & & & 1 & 0.035 \\
\hline growth $_{t}$ & & & & 1 \\
\hline
\end{tabular}

Sample period is 1881 to 2006 (126 years/observations). $\operatorname{LB}\left(Y_{t ;} ; n\right)$ is the Ljung-Box statistic for testing autocorrelation up to $n$ lags (distributed as chi-square with $n$ degrees of freedom), calculated for both the levels and the squares

temp $p_{t}$ refers to the first difference of the global mean temperature anomaly, $\Delta z_{t}$ to the change in anthropogenic forcings, $x_{t}$ to nonanthropogenic forcings and growth to $_{\text {torld GDP growth }}$

**Denotes significance at the $5 \%$ level

***Denote significance at the $1 \%$ level

apply a LM test to investigate whether a structural change has occurred in the correlations between the change in global mean temperature anomaly and the change in anthropogenic forcings. Next, we estimate the STCC-GARCH model to primarily determine the levels of anthropogenic forcings that change the pattern of this correlation and secondly the timing of this change. Finally, we apply a LM test to investigate whether another transition exists and, where appropriate, we extend the STCC-GARCH model and estimate the DSTCCGARCH model with more than one transition regimes in correlations.

Table 3, column 1, shows the estimated parameters of conditional correlations given by the constant conditional correlation (CCC) specification under the assumption of no regime shift between the two variables of interest. The results suggest that the conditional correlations are rather low (at 0.06), in line with the descriptive statistics. However, the question whether these correlations change over time remains unanswered and hence we proceed with the estimation of an STCC-GARCH model.

To assess whether the proposed time-varying STCCGARCH specification improves the model's ability to track the time-series properties of the data over a fixed parameter version, we employ the LM test developed by
Silvennoinen and Teräsvirta (2007). ${ }^{18}$ This test is designed to discriminate between the constant correlation GARCH model and the STCC-GARCH model and is applied to the residuals of Eqs. (1) and (2).

Under the null hypothesis, the LM statistic is asymptotically chi-square-distributed with one degree of freedom. The LM test does not discriminate between an increase and a decrease in correlation, but simply tests the null hypothesis of no change, $\mathrm{H}_{0}: \gamma=0$, against the alternative of $H_{a}: \gamma>0$, which implies a time-varying conditional correlation. To determine whether the correlation has increased or decreased, the STCC-GARCH model needs to be estimated. As stated earlier, based mainly on the volatile pattern of the plots of the series, we assume that both variables have time-varying conditional variances that follow a GARCH $(1,1)$ specification. ${ }^{19}$

The last row of Table 3 reports the LM statistics. The test in column 1 reveals that the null hypothesis of no structural change in the correlation between the change in global mean temperature anomaly and change in anthropogenic forcings is rejected at any conventional level of significance, supporting the notion of a regime switch in the conditional correlations.

The presence of one structural change in the correlation between the two variables implies a monotonic relationship. Following the estimation of an STCC-GARCH model with one structural change, we next examine for the existence of a second transition that allows for a nonmonotonic relationship which can capture more complicated patterns in time-varying correlations using the LM test developed by Silvennoinen and Teräsvirta [36]. The results in the last row of Table 3 (column 2 ) suggest that a second break exists.

These findings clearly demonstrate that it is not reasonable to assume that conditional correlations remain constant at all levels of anthropogenic forcings. Therefore, they are characterized by more than two dominant trends. To examine the direction and the pattern of change(s), we turn next to interpreting the estimation results of the STCC-GARCH and the DSTCC-GARCH models.

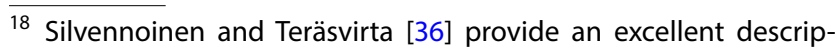
tion of the details of this test. Note that the unidentified parameter problem that exists under the null hypothesis is dealt using a Taylor series expansion, following Luukkonen et al. [22].

${ }^{19}$ We establish the adequacy of the model specification by performing standardized residual diagnostic tests. The mean and variance of the standardized residuals are found to have values of zero and one, respectively, for all cases. In addition, the Ljung-Box statistics in the standardized and squared standardized residuals show no evidence of linear dependence, suggesting that the model is well specified. These results are available upon request.
} 
Fig. 6 30-year rolling correlation of change in anthropogenic forcings and temperature

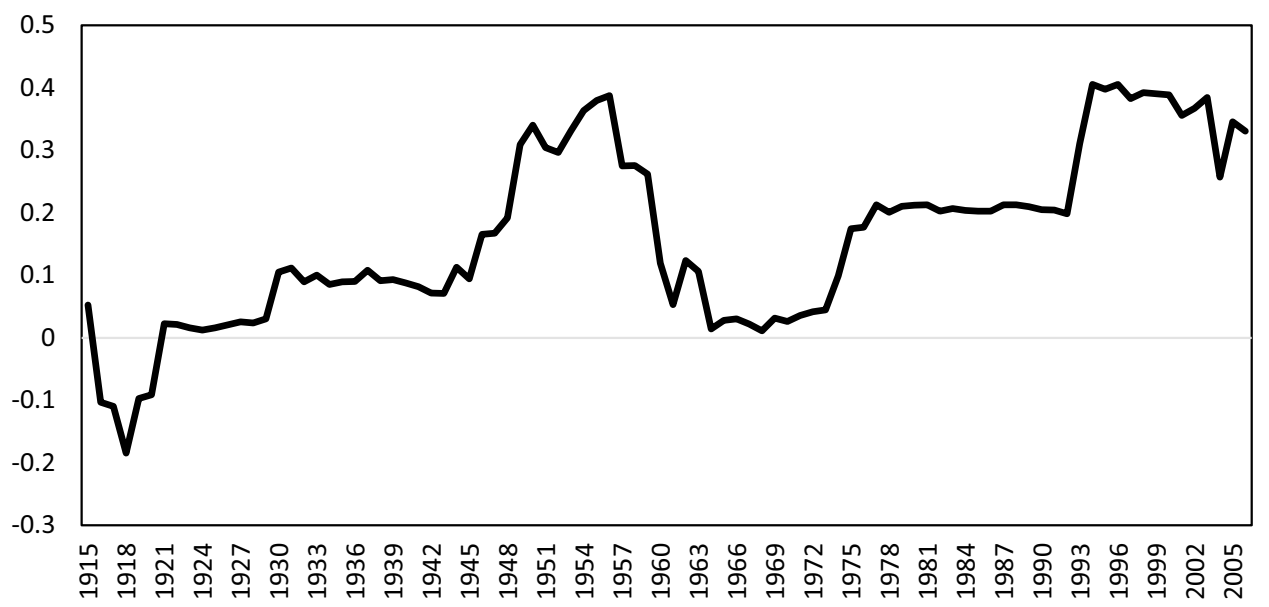

\subsection{Time-varying shifts in conditional correlations}

Based on the evidence provided by the LM tests, Tables 2 and 3 report the estimated parameters of the (D)STCCGARCH models described in Eqs. (1)-(11). ${ }^{20}$

Starting with mean equations (Table 2 , panels $A$ and $B$ ), the change in global mean temperature anomaly (temp $\mathrm{p}_{t}$ ) is negatively correlated with its lag value, but the effects of the change in anthropogenic forcings $\left(\Delta z_{t-1}\right)$ on temperature are insignificant. This finding may be attributed to the low levels of anthropogenic forcings for a long period of the dataset, as will be further demonstrated below. As for Eq. (2), anthropogenic forcings are predicted by their lag values with global mean temperature anomaly having insignificant effects. By employing a logistic function with time as a transition variable, the estimates suggest that there is a different behaviour of GDP growth on the change in anthropogenic forcings before and after the threshold point $\left(c_{g}=0.56\right)$ which corresponds to the period around 1960. More specifically, before 1960 the effect of GDP growth on anthropogenic forcings is essentially zero (negative but insignificant), while after it turns positive, suggesting that the increasing human activity regarding greenhouse gases has adverse effects on global temperature.

As far as the coefficients of the conditional covariance matrix of $\varepsilon_{t}$ are concerned (Table 2, panels $C$ and D), only the long-run persistence coefficients $\left(\xi_{1}\right.$ and $\left.\xi_{2}\right)$ of the volatility equations of the change in global mean temperature anomaly and the change in anthropogenic forcings are significant.

\footnotetext{
20 The results for the mean and variance equations of the CCC specification (not reported but available upon request) are qualitatively similar to those of the STCC and DSTCC specifications.
}

Therefore, the findings for GARCH specification should be interpreted with a note of caution since they belong to the extreme case in which the coefficient of $\sigma^{2}$ it- $1\left(\xi_{i}\right)$ is large, while the coefficient of $\varepsilon^{2}$ it- $1\left(a_{i}\right)$ is not significantly different from zero. In that case, the $\operatorname{GARCH}(1,1)$ model is not identified, i.e. it contains too many parameters, and the conditional variance equals the unconditional variance. In fact, the result of no GARCH is not surprising. It is extremely rare to find GARCH in annual time series. Clustering of volatility is typically observed only at much higher observation frequencies such as daily or weekly. For the STCC model, the lack of autoregressive conditional heteroskedasticity is not a problem. The diagonal matrices in the constant conditional correlation (CCC) or STCC decomposition can be scalar matrices. Their diagonal elements need not be of ARCH or GARCH type. ${ }^{21,22}$

Turning our attention to the examination of the transition functions, columns 2 and 3 of Table 3 report the conditional correlations in the regime prior to the threshold $\left(\rho_{0}\right)$, the regime after the threshold is surpassed $\left(\rho_{1}\right)$, and, in the DSTCC case, the regime following the second threshold value $\left(\rho_{2}\right)$. In addition, the locations (value) of the transitions ( $c_{1}$ and/or $\left.c_{2}\right)$, and, finally, the shape (abruptness) of the transitions $\left(\gamma_{1}\right.$ and/or $\left.\gamma_{2}\right)$ are also reported.

Starting with the case of a single break in conditional correlations (Table 3, column 2), the estimated parameter $c_{1}$ suggests that when the level of anthropogenic forcings is above 0.945 the correlation changes from zero (insignificant) to positive 0.544 with the transition being abrupt

\footnotetext{
${ }^{21}$ We thank an anonymous referee for pointing this out.

22 In addition to the model presented in the paper, we estimate the model without GARCH specification. The results remain qualitatively the same (available upon request), and therefore, we opt to use and present the original model with the GARCH specification to safeguard the case where the volatility clustering has been existed.
} 
Table 2 Estimated parameters for mean and variance equations

\begin{tabular}{|c|c|c|}
\hline Parameters & $\begin{array}{l}\text { STCC } \\
(1)\end{array}$ & $\begin{array}{l}\text { DSTCC } \\
(2)\end{array}$ \\
\hline \multicolumn{3}{|c|}{ A. Mean Eq. 1: temp $p_{t}$} \\
\hline$\beta_{0}$ & $\begin{array}{l}3.055^{*} \\
(1.756)\end{array}$ & $\begin{array}{l}3.455^{* *} \\
(1.671)\end{array}$ \\
\hline$\beta_{1}$ & $\begin{array}{l}-0.266^{* * *} \\
(0.089)\end{array}$ & $\begin{array}{l}-0.284^{* * *} \\
(0.089)\end{array}$ \\
\hline$\beta_{2}$ & $\begin{array}{l}2.854^{*} \\
(1.584)\end{array}$ & $\begin{array}{l}3.074^{* *} \\
(1.477)\end{array}$ \\
\hline$\beta_{3}$ & $\begin{array}{l}-0.513 \\
(0.618)\end{array}$ & $\begin{array}{l}-0.575 \\
(0.579)\end{array}$ \\
\hline \multicolumn{3}{|c|}{ B. Mean Eq. $2: \Delta z_{t}$} \\
\hline$\delta_{0}$ & $\begin{array}{l}0.188^{* *} \\
(0.085)\end{array}$ & $\begin{array}{l}0.167^{* *} \\
(0.084)\end{array}$ \\
\hline$\delta_{1}$ & $\begin{array}{l}0.006^{* *} \\
(0.003)\end{array}$ & $\begin{array}{l}0.007^{* *} \\
(0.003)\end{array}$ \\
\hline$\delta_{2}$ & $\begin{array}{l}0.849^{* * * *} \\
(0.038)\end{array}$ & $\begin{array}{l}0.861^{* * *} \\
(0.054)\end{array}$ \\
\hline$\delta_{3}$ & $\begin{array}{l}-0.032 \\
(0.025)\end{array}$ & $\begin{array}{l}-0.032 \\
(0.026)\end{array}$ \\
\hline$\delta_{4}$ & $\begin{array}{l}0.037^{* *} \\
(0.018)\end{array}$ & $\begin{array}{l}0.032^{* * *} \\
(0.014)\end{array}$ \\
\hline$c_{g}$ & $0.560^{* * *}$ & $0.560^{* * *}$ \\
\hline $\begin{array}{l}\gamma_{g} \\
\text { C. Condition }\end{array}$ & 25.62 & 27.44 \\
\hline$\omega_{1}$ & $\begin{array}{l}12.55^{* * * *} \\
(3.13)\end{array}$ & $\begin{array}{l}13.37^{* * *} \\
(3.29)\end{array}$ \\
\hline$a_{1}$ & $\begin{array}{l}0.000 \\
(0.337)\end{array}$ & $\begin{array}{l}0.000 \\
(0.001)\end{array}$ \\
\hline$\xi_{1}$ & $\begin{array}{l}0.897^{* * *} \\
(0.131)\end{array}$ & $\begin{array}{l}0.892^{* * *} \\
(0.143)\end{array}$ \\
\hline \multicolumn{3}{|c|}{ D. Conditional variance Eq. $1: z_{\mathrm{t}}$} \\
\hline$\omega_{2}$ & $\begin{array}{l}0.038 \\
(1.604)\end{array}$ & $\begin{array}{l}0.038 \\
(2.162)\end{array}$ \\
\hline$a_{2}$ & $\begin{array}{l}0.314 \\
(0.193)\end{array}$ & $\begin{array}{l}0.319 \\
(0.240)\end{array}$ \\
\hline$\xi_{2}$ & $\begin{array}{l}0.543^{* * *} \\
(0.127)\end{array}$ & $\begin{array}{l}0.536^{* *} \\
(0.203)\end{array}$ \\
\hline
\end{tabular}

E. Other information

$L(\theta)$

$-570.0$

$-559.33$

Transition variable is anthropogenic forcings $\left(z_{t}\right)$ for both specifications (STCC and DSTCC)

${ }^{*},{ }^{* *},{ }^{* * *}$ Indicate statistical significance at the $10 \%, 5 \%$ and $1 \%$ level, respectively. Parentheses contain the standard errors, $L(\theta)$ is the log-likelihood value
Table 3 Estimated parameters for conditional correlation

\begin{tabular}{llll}
\hline Parameters & $\begin{array}{l}\text { CCC } \\
(1)\end{array}$ & $\begin{array}{l}\text { STCC } \\
(2)\end{array}$ & $\begin{array}{l}\text { DSTCC } \\
(3)\end{array}$ \\
\hline Correlations & & & \\
$\rho_{(0)}$ & 0.061 & -0.067 & -0.074 \\
& $(0.624)$ & $(0.618)$ & $(0.623)$ \\
$\rho_{(1)}$ & - & $0.544^{* * *}$ & 0.521 \\
& & $(0.254)$ & $(0.244)$ \\
$\rho_{(2)}$ & - & & 0.809 \\
& & & $(0.073)$ \\
Transition parameters & & & \\
$c_{(1)}$ & - & $0.945^{* * *}$ & 0.949 \\
& - & $(0.037)$ & $(0.025)$ \\
$c_{(2)}$ & - & - & 2.395 \\
& & & $(0.011)$ \\
$\gamma_{(1)}$ & - & $()$. & 100 \\
$\gamma_{(2)}$ & & - & $()$. \\
& & & 100 \\
\hline
\end{tabular}

Transition variable is anthropogenic forcings $\left(z_{t}\right)$ for both specifications (STCC and DSTCC). Parentheses contain the standard errors

as $\gamma_{1}$ indicates. ${ }^{23}$ The value of this threshold can be traced back in the mid-1960s, during the years of the post-WWII economic boom, when a substantial amount of additional greenhouse gases (compared to the pre-industrial era) had started accumulating in the atmosphere due to the combustion of fossil fuels from human activities (see also Fig. 2) ${ }^{24}$ Intuitively, this suggests that after the 1960 s a $1 \%$ change in anthropogenic forcings coincided with a $0.5 \%$ change in temperature anomaly. Nevertheless, the LM test suggests that a second break in correlations should be included; therefore, we proceed with the estimation of the DSTCC specification.

In this case, the estimated parameters for $c_{1}$ and $c_{2}$ are equal to 0.949 and 2.395 , respectively, with the first threshold value being in line with the STCC results as overviewed in the previous paragraph. Conditional correlations, similar to the STCC case, vary from zero (insignificant) in the case of $\rho_{0}$ when the level of anthropogenic forcings is below $c_{1}$, to 0.521 in the second regime $\left(\rho_{1}\right)$ when the level of anthropogenic forcings is between 0.949 and 2.395; the correlation between the change in anthropogenic forcings and the change in temperature anomaly further increases to 0.809 when the second threshold (2.395) is surpassed.

\footnotetext{
${ }^{23}$ It should be noted that the correlation is a correlation between errors of the conditional mean model, not a correlation between the variables themselves.

${ }^{24}$ This period coincides with the timing of the GDP threshold in the second equation.
} 


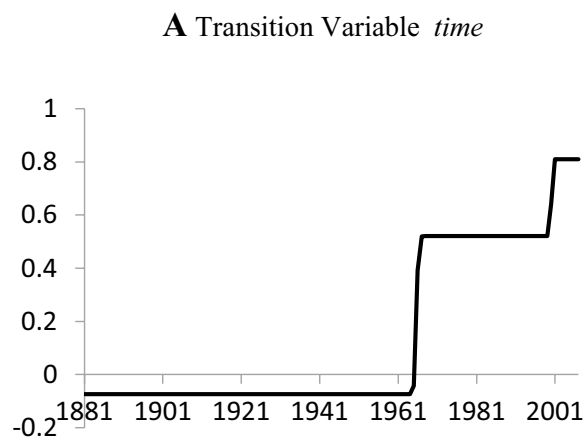

Fig. 7 Double smooth transition conditional correlation. Notes: The first figure depicts the timing of the changes, using time as the transition variable (Panel a-solid line) for both logistic functions in

Once again, the transition from one level to the other is abrupt as $\gamma$ parameters suggest. As for the timing of the changes, the first one takes place around 1960 (confirming the pattern of the STCC specification), while the second around 1990. Figure 7 (Panels a and b) provides a graphical illustration of the changes using time as the transition variable (Panel a-solid line) for both logistic functions in the DSTCC specification, while the second (Panel b-dotted line) uses lag anthropogenic forcings as the transition variable for both logistic functions in the DSTCC specification. The plots confirm that the time of change coincides with the change in the levels of the anthropogenic forcings.

For more details on the time of the change, the following section provides additional estimations, including a robustness check based on a different dataset.

\subsection{Identifying climate change in time and robustness checks}

As suggested above, the timing of the changes in correlation is important for understanding the behaviour of the series under study. As such, this section aims to identify the specific time of change, while a different dataset is employed as robustness check and validity of previous findings.

Firstly, Eqs. (1-11) are re-estimated using time as the transition variable. In this manner, the threshold point identifies the exact point of change in the conditional correlation, between changes in anthropogenic forcings and changes in temperature anomaly, irrespective of the level of forcings at that point in time. The results for conditional correlations are reported in Table 4, column 1 (for STCC specification) and column 2 (for DSTCC specification), respectively. ${ }^{25}$ Threshold point for the STCC is given

\footnotetext{
25 The results for mean and variance equations (available upon request) remain qualitatively the same for all estimations in this section.
}

B Transition Variable lag anthropogenic forcings

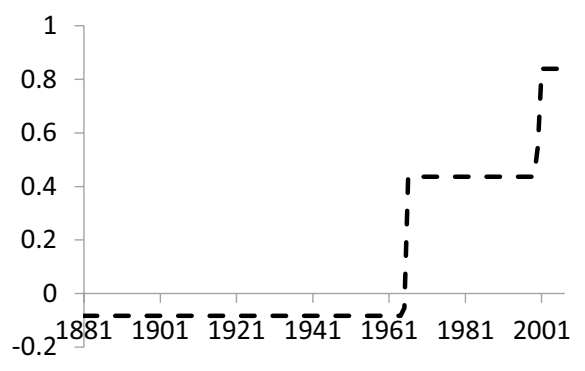

the DSTCC specification, while the second uses lag anthropogenic forcings as the transition variable (Panel $\mathbf{b}$-dotted line) for both logistic functions in the DSTCC specification

at 0.567 (located around the mid-1950s) a result which is in accordance with the findings of the previous section when anthropogenic forcings were used as the transition variable. The findings of the previous section are also confirmed when using the DSTCC specification where the first threshold point $\left(c_{1}\right)$ is the same with the STCC model, while the second $\left(c_{2}\right)$ equals 0.964 (around 1990s). Furthermore, the pattern of conditional correlation is qualitatively similar to previous estimations, with the value after the second threshold standing at 0.77 compared to 0.81 in the previous section.

In addition to the above, a different dataset is utilized and the DSTCC specification is re-estimated using both anthropogenic forcings and time as transition variables. The new dataset is employed to cross-check the above results as the forcings variables previously used are not obtained via direct observation, but are model estimates. To account for any potential loss of information due to this issue, the remainder of this section provides additional estimations of the short-run effects of changes in anthropogenic forcings on the change in temperature anomaly using observational data from Stern and Kaufmann [37]. ${ }^{26}$ The full description of the dataset is given in Appendix.

These findings are presented in Table 4, column 3 for the DSTCC with anthropogenic forcings as the transition variable and column 4 for the DSTCC with time as the transition variable. Once again structural changes in conditional correlations and their timing are in accordance with the findings reported earlier and suggest that the post-WWII economic boom is crucial for the adverse effects on climate change. In addition, they also support the view that another change in the correlation occurred in the 1990s.

${ }^{26}$ We thank Trude Storelvmo and Robert Kaufman for pointing this issue. 
Table 4 Location of change in time and alternative dataset

\begin{tabular}{|c|c|c|c|c|}
\hline Parameters & $\begin{array}{l}\text { STCC } \\
(1)\end{array}$ & $\begin{array}{l}\text { DSTCC } \\
(2)\end{array}$ & $\begin{array}{l}\text { DSTCC } \\
\text { (3) }\end{array}$ & $\begin{array}{l}\text { DSTCC } \\
\text { (4) }\end{array}$ \\
\hline Transition variable: & Time & Time & $z_{t}$ & Time \\
\hline Dataset: & Original & Original & Stern and Kaufmann & $\begin{array}{l}\text { Stern and } \\
\text { Kaufmann }\end{array}$ \\
\hline \multicolumn{5}{|l|}{ Correlations: } \\
\hline$\rho_{(0)}$ & $\begin{array}{l}-0.073 \\
(0.614)\end{array}$ & $\begin{array}{l}-0.068 \\
(0.621)\end{array}$ & $\begin{array}{l}0.062 \\
(0.613)\end{array}$ & $\begin{array}{c}-0.183 \\
(0.596)\end{array}$ \\
\hline$\rho_{(1)}$ & $\begin{array}{l}0.414 \\
(0.159)\end{array}$ & $\begin{array}{l}0.378 \\
(0.599)\end{array}$ & $\begin{array}{l}0.466 \\
(0.128)\end{array}$ & $\begin{array}{l}0.192 \\
(0.106)\end{array}$ \\
\hline$\rho_{(2)}$ & & $\begin{array}{l}0.766 \\
(0.098)\end{array}$ & $\begin{array}{l}0.849 \\
(0.099)\end{array}$ & $\begin{array}{l}0.866 \\
(0.011)\end{array}$ \\
\hline \multicolumn{5}{|l|}{ Transition parameters } \\
\hline$c_{(1)}$ & $\begin{array}{l}0.567 \\
(0.169)\end{array}$ & $\begin{array}{l}0.537 \\
(0.005)\end{array}$ & $\begin{array}{l}0.537 \\
(0.001)\end{array}$ & $\begin{array}{l}0.538 \\
(0.027)\end{array}$ \\
\hline$c_{(2)}$ & - & $\begin{array}{l}0.964 \\
(0.001)\end{array}$ & $\begin{array}{l}0.955 \\
(0.001)\end{array}$ & $\begin{array}{l}0.954 \\
(0.001)\end{array}$ \\
\hline$\gamma_{(1)}$ & $\begin{array}{l}100 \\
\text { (.) }\end{array}$ & $\begin{array}{l}100 \\
\text { (.) }\end{array}$ & $\begin{array}{l}100 \\
(.)\end{array}$ & $\begin{array}{l}100 \\
(.)\end{array}$ \\
\hline$\gamma_{(2)}$ & - & $\begin{array}{l}100 \\
\text { (.) }\end{array}$ & $\begin{array}{l}100 \\
\text { (.) }\end{array}$ & $\begin{array}{l}100 \\
\text { (.) }\end{array}$ \\
\hline$L(\theta)$ & -571.2 & -559.33 & -1052.21 & -1028.8 \\
\hline
\end{tabular}

Parentheses contain the standard errors
Overall, the results of the last two sections provide evidence that, under either single or double smooth transition conditional correlation specification using observational or model-based data with either time or anthropogenic forcings as the transition variable, the change in greenhouse gases and their accumulation in the atmosphere in recent decades have significantly contributed to global warming.

\section{Conclusions}

In its latest Synthesis Report, the Intergovernmental Panel on Climate Change emphasized that human influence on the climate system is clear and growing. Many of the observed changes since the 1950s are unprecedented over decades to millennia and it is "extremely likely" that more than half of the observed increase in global average surface temperature from 1951 to 2010 was caused by the anthropogenic increase in greenhouse gas concentrations and other anthropogenic forcings together. In addition, they stressed that the more the human activities disrupt the climate, the greater the risks of severe, pervasive and irreversible impacts for people and ecosystems [20, p. 40 \& 48].
Our econometric analysis confirms the above findings of climate science. By employing a time-varying conditional correlation specification for the first time in climaterelated research, we find that the effect of a change in anthropogenic forcings on global temperature changes started becoming significant only after WWII, with the correlation between the two jumping to 0.5 , suggesting that half of the change is passed on to temperature, a finding similar to the IPCC. This identifies a nonlinear relationship between temperature and anthropogenic forcings, which indicates that the effect of humans on climate is very likely to become more important in the future. Thus, the severity of climate change impacts may worsen in the coming decades. Moreover, the analysis sheds light into the short-run effects of human activities on temperature change, a valuable insight for climate scientists which most previous studies have overlooked due to the methodology employed. Our results are robust to alternative specifications and to estimations with a different dataset.

\section{Compliance with ethical standards}

Conflict of interest The authors declare that they have no conflict of interest. 


\section{Appendix 1}

From the above, the anthropogenic forcings $\left(z_{t}\right)$ series is defined as:

$$
\begin{aligned}
z_{t}= & \mathrm{WMGHG}_{t}+\mathrm{O}_{t}+\text { LandUse }_{t}+\text { Snowalb }_{t} \\
& + \text { TropDir }_{t}+\text { Troplnd }_{t^{\prime}}
\end{aligned}
$$

where $\mathrm{WMGHG}_{t}, \mathrm{O}_{t}$, LandUse $_{t}$, Snowalb ${ }_{t}$, TropDir $_{t}$ and Troplnd ${ }_{t}$ as defined as in "Appendix 1", Table 5. Similarly, the series for natural (non-anthropogenic) forcings $\left(x_{t}\right)$ is defined as:

$x_{t}=$ StratAer $_{t}+$ Solar $_{t}+$ Orbital $_{t}$ in which StratAer ${ }_{t}$, Solar $_{t}$ and Orbital ${ }_{t}$ are refer to the definitions in "Appendix 1", Table 5.

As defined in Table 5, world GDP is compiled as the sum of the national GDP of Australia, Austria, Belgium, Canada, Denmark, Finland, France, Germany, India, Italy, Japan, the Netherlands, New Zealand, Norway, Portugal, Spain, Sri Lanka, Sweden, Switzerland, the UK and the USA. Data range from 1884 to 2006 and were obtained from Maddison [23].

\section{Appendix 2}

From the above, the anthropogenic forcings $\left(z_{t}\right)$ series is defined as:

Table 5 Data sources and definitions

\begin{tabular}{llllll}
\hline Variable name & Short name & Unit & Range & Data source & Link \\
\hline Well-mixed greenhouse gas & WMGHG $_{t}$ & $\mathrm{Wm}^{-2}$ & $1880-2012$ & Miller et al. [27] & http://data.giss.nasa.gov/modelforce/ \\
Ozone & $\mathrm{O}_{t}$ & $\mathrm{Wm}^{-2}$ & $1880-2012$ & Miller et al. [27] & http://data.giss.nasa.gov/modelforce/ \\
Land human use & LandUse $_{t}$ & $\mathrm{Wm}^{-2}$ & $1880-2012$ & Miller et al. [27] & http://data.giss.nasa.gov/modelforce/ \\
Black carbon snow albedo & Snowalb $_{t}$ & $\mathrm{Wm}^{-2}$ & $1880-2012$ & Miller et al. [27] & http://data.giss.nasa.gov/modelforce/ \\
Tropospheric aerosols (direct) & TropDir $_{t}$ & $\mathrm{Wm}^{-2}$ & $1880-2012$ & Miller et al. [27] & http://data.giss.nasa.gov/modelforce/ \\
Tropospheric aerosols (indirect) & Troplnd $_{t}$ & $\mathrm{Wm}^{-2}$ & $1880-2012$ & Miller et al. [27] & http://data.giss.nasa.gov/modelforce/ \\
Stratospheric aerosols & StratAer $_{t}$ & $\mathrm{Wm}^{-2}$ & $1880-2012$ & Miller et al. [27] & http://data.giss.nasa.gov/modelforce/ \\
Solar irradiance & $\mathrm{Wolar}_{t}$ & $\mathrm{Wm}^{-2}$ & $1880-2012$ & Miller et al. [27] & http://data.giss.nasa.gov/modelforce/ \\
Orbital variations & Orbital $_{t}$ & $\mathrm{Wm}^{-2}$ & $1880-2012$ & Miller et al. [27] & http://data.giss.nasa.gov/modelforce/ \\
Temperature anomaly & temp $_{t}$ & ${ }^{\circ} \mathrm{C}$ & $1880-2015$ & GlSS & http://data.giss.nasa.gov/gistemp/ \\
World GDP & $\mathrm{GDP}$ & $\mathrm{GK} \mathrm{Dollars}$ & $1884-2006$ & Maddison [23] & http://www.ggdc.net/maddison/ \\
\hline
\end{tabular}

\begin{tabular}{|c|c|c|c|c|c|}
\hline Variable name & Short name & Unit & Range & Data source & Link \\
\hline $\begin{array}{l}\text { Radiative forcing of carbon } \\
\text { dioxide }\end{array}$ & $\mathrm{RFCO}_{t}$ & $\mathrm{Wm}^{-2}$ & $1850-2011$ & Stern and Kaufmann [37] & $\begin{array}{l}\text { http://www.sterndavidi.com/publi } \\
\text { cations_type.html }\end{array}$ \\
\hline Radiative forcing of methane & $\mathrm{RFCH} 4_{t}$ & $\mathrm{Wm}^{-2}$ & $1850-2011$ & Stern and Kaufmann [37] & $\begin{array}{l}\text { http://www.sterndavidi.com/publi } \\
\text { cations_type.html }\end{array}$ \\
\hline $\begin{array}{l}\text { Radiative forcing of dinitrogen } \\
\text { oxide }\end{array}$ & RFN20 $t$ & $\mathrm{Wm}^{-2}$ & $1850-2011$ & Stern and Kaufmann [37] & $\begin{array}{l}\text { http://www.sterndavidi.com/publi } \\
\text { cations_type.html }\end{array}$ \\
\hline Radiative forcing of CFC11 & $\mathrm{RFCFC} 11_{t}$ & $\mathrm{Wm}^{-2}$ & $1850-2011$ & Stern and Kaufmann [37] & $\begin{array}{l}\text { http://www.sterndavidi.com/publi } \\
\text { cations_type.html }\end{array}$ \\
\hline Radiative forcing of CFC12 & $\mathrm{RFCFC} 12_{t}$ & $\mathrm{Wm}^{-2}$ & $1850-2011$ & Stern and Kaufmann [37] & $\begin{array}{l}\text { http://www.sterndavidi.com/publi } \\
\text { cations_type.html }\end{array}$ \\
\hline $\begin{array}{l}\text { Radiative forcing of anthropo- } \\
\text { genic sulphur emissions }\end{array}$ & RFSOX $_{t}$ & $\mathrm{Wm}^{-2}$ & $1850-2011$ & Stern and Kaufmann [37] & $\begin{array}{l}\text { http://www.sterndavidi.com/publi } \\
\text { cations_type.html }\end{array}$ \\
\hline Radiative forcing of black carbon & $\mathrm{RFBC}_{t}$ & $\mathrm{Wm}^{-2}$ & $1850-2011$ & Stern and Kaufmann [37] & $\begin{array}{l}\text { http://www.sterndavidi.com/publi } \\
\text { cations_type.html }\end{array}$ \\
\hline $\begin{array}{l}\text { Radiative forcing of solar irradi- } \\
\text { ance }\end{array}$ & $\mathrm{RFSOLAR}_{t}$ & $\mathrm{Wm}^{-2}$ & $1850-2011$ & Stern and Kaufmann [37] & $\begin{array}{l}\text { http://www.sterndavidi.com/publi } \\
\text { cations_type.html }\end{array}$ \\
\hline $\begin{array}{l}\text { Radiative forcing of stratospheric } \\
\text { sulphates }\end{array}$ & $\mathrm{RFVOL}_{t}$ & $\mathrm{Wm}^{-2}$ & $1850-2011$ & Stern and Kaufmann [37] & $\begin{array}{l}\text { http://www.sterndavidi.com/publi } \\
\text { cations_type.html }\end{array}$ \\
\hline Temperature anomaly & temp $_{t}$ & ${ }^{\circ} \mathrm{C}$ & $1850-2011$ & HADCRUT4 & $\begin{array}{l}\text { http://www.sterndavidi.com/publi } \\
\text { cations_type.html }\end{array}$ \\
\hline World GDP & GDP & GK Dollars & 1884-2006 & Maddison [23] & http://www.ggdc.net/maddison/ \\
\hline
\end{tabular}

Table 6 Data sources and definitions 


$$
\begin{aligned}
z_{t}= & \mathrm{RFCO}_{t}+\mathrm{RFCH}_{t}+\mathrm{RFN}_{2} 0_{t}+\mathrm{RFCFC}_{1} 1_{t} \\
& +\mathrm{RFCFC}_{1} 2_{t}+\mathrm{RFSOX}_{t},
\end{aligned}
$$

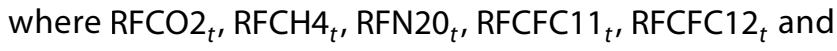
RFSOX $_{t}$ are as defined in "Appendix 2", Table 6 (this definition can also be found as the RFANTH variable in Stern and Kaufmann [37]). Similarly, the series for natural (nonanthropogenic) forcings $\left(x_{t}\right)$ is defined as:

$x_{t}=\mathrm{RFSOLAR}_{t}+\mathrm{RFVOL}_{t}$

in which RFSOLAR ${ }_{t}$ and $\mathrm{RFVOL}_{t}$ refer to the definitions in "Appendix 2", Table 5. This definition corresponds to the RFNAT definition of natural forcings in Stern and Kaufmann [37]. Real GDP is defined as in "Appendix 1".

\section{References}

1. Attanasio A, Pasini A, Triacca U (2012) A contribution to attribution of recent global warming by out-of-sample Granger causality analysis. Atmospheric Science Letters 13(1):67-72

2. Babiy AP, Kharytonov MM, Gritsan NP (2003) Connection between emissions and concentrations of atmospheric pollutants. In: Melas D, Syrakov D (eds) Air pollution processes in regional scale, NATO science series, IV: earth and environmental sciences. Kluwer Academic Publishers, The Netherlands, pp 11-19

3. Beenstock M, Reingewertz Y, Paldor N (2012) Polynomial cointegration tests of anthropogenic impact on global warming. Earth Syst Dyn 3(2):173-188

4. Berben RP, Jansen WJ (2005) Comovement in international equity markets: a sectoral view. J Int Money Finance 24(5):832-857

5. Boden TA, Marland G, Andres RJ (2016) Global, regional, and national fossil-fuel $\mathrm{CO} 2$ emissions. Carbon Dioxide Information Analysis Center, Oak Ridge National Laboratory, U.S. Department of Energy, Oak Ridge, Tenn. https://doi. org/10.3334/CDIAC/00001_V2016

6. Bollerslev T, Wooldridge J (1992) Quasi-maximum likelihood estimation and inference in dynamic models with time varying covariances. Econometric Rev 11(2):143-172

7. Campbell SD, Diebold FX (2005) Weather forecasting for weather derivatives. J Am Stat Assoc 100(469):6-16

8. Chevillon $\mathrm{G}$ (2017) Robust cointegration testing in the presence of weak trends, with an application to the human origin of global warming. Econom Rev 36(5):514-545

9. Dergiades T, Kaufmann RK, Panagiotidis T (2016) Long-run changes in radiative forcing and surface temperature: the effect of human activity over the last five centuries. J Environ Econ Manag 76:67-85

10. Estrada F, Perron P, Martínez-López B (2013) Statistically derived contributions of diverse human influences to twentieth-century temperature changes. Nat Geosci 6(12):1050-1055

11. Fang $K$, Chen $D$, Ilvonen $L$, Frank $D$, Pasanen $L$, Holmström $L$, Zhao Y, Zhang P, Seppä H (2018) Time-varying relationships among oceanic and atmospheric modes: a turning point at around 1940. Quatern Int 487:12-25

12. Frölicher TL, Fischer EM, Gruber N (2018) Marine heatwaves under global warming. Nature 560(7718):360
13. Gervais $F$ (2016) Anthropogenic $\mathrm{CO} 2$ warming challenged by 60-year cycle. Earth Sci Rev 155:129-135

14. GISTEMP Team (2016) GISS surface temperature analysis (GISTEMP). NASA Goddard Institute for Space Studies. Dataset accessed 2016-07-05 at http://data.giss.nasa.gov/gistemp/

15. Goodwin BK, Holt MT, Prestemon JP (2011) North American oriented strand board markets, arbitrage activity, and market price dynamics: a smooth transition approach. Am J Agr Econ 93(4):993-1014

16. Hamilton JD (2008) Macroeconomics and ARCH (No. w14151). National Bureau of Economic Research

17. Hansen J, Nazarenko L, Ruedy R, Sato M, Willis J, Del Genio A, Koch D, Lacis A, Lo K, Menon S, Novakov T, Perlwitz J, Russell G, Schmidt GA, Tausnev N (2005) Earth's energy imbalance: confirmation and implications. Science 308(5727):1431-1435

18. Hansen J, Ruedy R, Sato M, Lo K (2010) Global surface temperature change. Rev Geophys 48(4):1-29

19. Hsiang S (2016) Climate econometrics. Ann Rev Resour Econ 8:43-75

20. IPCC (2014) Climate change 2014: synthesis report. Contribution of working groups I, II and III to the fifth assessment report of the intergovernmental panel on climate change [Core Writing Team RK Pachauri and LA Meyer (eds.)]. IPCC, Geneva, Switzerland, 151 pp, ISBN 978-92-9169-143-2

21. Leggett LMW, Ball DA (2015) Granger causality from changes in level of atmospheric $\mathrm{CO} 2$ to global surface temperature and the El Niño-Southern Oscillation, and a candidate mechanism in global photosynthesis. Atmos Chem Phys 15(20):11571-11592

22. Luukkonen R, Saïkkonen P, Teräsvirta T (1988) Testing linearity against smooth transition autoregressive models. Biometrika 75(3):491-499

23. Maddison A (2009) Population levels, GDP levels and per capita GDP levels, 1-2006 AD. Historical Statistics for the World Economy: 1-2006 AD. Retrieved 5 July 2016 from http://www.ggdc. net/maddison/

24. Marshall J, Plumb RA (2008) Atmosphere, ocean, and climate dynamics: an introductory text. Academic Press, Cambridge

25. Mazzocchi F, Pasini A (2017) Climate model pluralism beyond dynamical ensembles. Wiley Interdiscip Rev Clim Change 8(6):e477

26. Meinshausen M, Smith SJ, Calvin K, Daniel JS, Kainuma MLT, Lamarque JF, Matsumoto K, Montzka SA, Raper SC, Riahi K, Thomson AGJMV (2011) The RCP greenhouse gas concentrations and their extensions from 1765 to 2300 . Clim Change 109(1-2):213

27. Miller RL, Schmidt GA, Nazarenko LS, Tausnev N, Bauer SE, DelGenio AD, Kelley M, Lo KK, Ruedy R, Shindell DT, Aleinov I (2014) CMIP5 historical simulations (1850-2012) with GISS ModelE2. J Adv Model Earth Syst 6(2):441-478

28. NASA: Climate Forcings and Global Warming. January 14, 2009. Retrieved from https://earthobservatory.nasa.gov/Features/ EnergyBalance/page7.php

29. National Research Council (2001) Climate change science: an analysis of some key questions. National Academies Press, Washington. https://doi.org/10.17226/10139

30. Pasini A, Triacca U, Attanasio A (2012) Evidence of recent causal decoupling between solar radiation and global temperature. Environ Res Lett 7(3):034020

31. Pasini $A$, Lorè $M$, Ameli $F$ (2006) Neural network modelling for the analysis of forcings/temperatures relationships at different scales in the climate system. Ecol Model 191(1):58-67

32. Peixoto J, Oort A (1992) Physics of climate. American Institute of Physics Press, Woodbury

33. Pretis F, Allen M (2013) Climate science: breaks in trends. Nat Geosci 6(12):992-993 
34. Pretis F, Hendry DF (2013) Comment on" Polynomial cointegration tests of anthropogenic impact on global warming" by Beenstock et al.(2012) — some hazards in econometric modelling of climate change. Earth Syst Dyn 4(2):375-384

35. Silvennoinen A, Teräsvirta T (2015) Modeling conditional correlations of asset returns: a smooth transition approach. Econom Rev 34(1-2):174-197

36. Silvennoinen A, Teräsvirta T (2009) Modeling multivariate autoregressive conditional heteroskedasticity with the double smooth transition conditional correlation GARCH model. J Financ Econom 7(4):373-411

37. Stern DI, Kaufmann RK (2014) Anthropogenic and natural causes of climate change. Clim Change 122(1-2):257-269

38. Stips A, Macias D, Coughlan C, Garcia-Gorriz E, San Liang X (2016) On the causal structure between $\mathrm{CO} 2$ and global temperature. Sci Rep 6:21691

39. Teräsvirta T (1998) Modeling economic relationships with smooth transition regressions. In: Ullah A, Giles DEA (eds)
Handbook of applied economic statistics. Dekker, New York, pp 507-552

40. Teräsvirta T, Tjøstheim D, Granger CWJ (2010) Modelling nonlinear economic time series. Oxford University Press, Oxford

41. Triacca U, Attanasio A, Pasini A (2013) Anthropogenic global warming hypothesis: testing its robustness by Granger causality analysis. Environmetrics 24(4):260-268

42. Yin J, Overpeck J, Peyser C, Stouffer R (2018) Big jump of record warm global mean surface temperature in 2014-2016 related to unusually large oceanic heat releases. Geophys Res Lett 45(2):1069-1078

Publisher's Note Springer Nature remains neutral with regard to jurisdictional claims in published maps and institutional affiliations. 